\title{
EVALUATION OF URETEROCYSTOPLASTY AS AN ALTERNATIVE FOR AUGMENTATION ILIOCYSTOPLASTY IN THE PRESENCE OF DILATED URETERS
}

\author{
Mohammed Sherif Mourad, Youssef Mahmoud Kotb, and \\ Ahmad Hefnawy Mohammad
}

\begin{abstract}
Department Urology, Faculty of Medicine, Ain Shams University

Corresponding:

Ahmad Hefnawy Mohammad

Mobile: +201012316122

Email:

ahmad_hefnawy@hotmail.com

Received: 4/3/2020

Accepted: 31/3/2020
\end{abstract}

Online ISSN: 2735-3540

\begin{abstract}
:
Background: Ureterocystoplasty has been considered as an alternative for iliocystoplasty when there is dilated ureters in association with renal impairment/extensive ileal resection, several studies reported variable results after ureterocystoplasty
\end{abstract}

Aim of the work: To compare the outcomes of augmentation ureterocystoplasty in patients with dilated ureters to conventional augmentation iliocystoplasty in patients who can undergo both procedures.

Patients and Methods: In a prospective randomized clinical study, 10 patients will undergo ureterocystoplasty; another 10 patients will undergo iliocystoplasty.

The inclusion criteria include patients with unilateral or bilateral ureteric dilatation after failure of conservative measures. The Exclusion criteria were insufficient ureteric dilatation, elevated S.creat. or previous extensive ileal resection

Results: Our results showed significant improvement in capacity and compliance in all groups, the degree of urodynamic improvement was however inferior when the distal segment of 2 ureters were used for augmentation versus the use of ileum or an entire ureter of a nonfunctioning kidney, the degree of hydronephrosis improved or resolved in all patients, continence improved in all patients despite the requirement for CIC in most patients, the frequency of urinary tract infections was similar in both groups.

Conclusions: Our study concludes that augmentation with sufficient amount of ureteric tissue provides adequate augmentation with similar urodynamic outcome to augmentation with the use of ileum, however if the ureteric tissue used was insufficient such as when using the distal segment of 1 or 2 ureters especially when the ureters are not sufficiently dilated the improvement in urodynamic outcome was inferior to the use of ileum.

Key Words: ureterocystoplasty, augmentation, neurogenic bladder, posterior urethral valves, urodynamic.

\section{INTRODUCTION:}

Bladder augmentation or augmentation cystoplasty is the addition of a segment of bowel or other suitable tissue to the in-situ bladder to increase capacity, improve compliance, or treat uncontrollable detrusor contractility. It is frequently used in the reconstruction of neurogenic bladders that have failed medical therapy or other conservative therapies ${ }^{(\mathbf{1})}$. 
The majority of patients requiring augmentation cystoplasty have smallcapacity, noncompliant, or hypertonic bladders as a result of neuropathicity, from myelodysplasia or traumatic spinal cord injury, or myogenic failure, from posterior urethral valves. On occasion, augmentation cystoplasty is required to provide adequate bladder volume in cases of classic extrophy, cloacal extrophy, and cloacal malformations. Bladder dysfunction should initially be treated with anticholinergic medications and clean intermittent catheterization (CIC) in an effort to diminish neurogenic detrusor overactivity, improve compliance, and provide regular and effective bladder emptying. When urodynamic evidence exists that nonoperative measures have failed, augmentation cystoplasty is indicated. Intravesical storage pressure greater than 40 $\mathrm{cm} \mathrm{H} 2 \mathrm{O}$ is the most robust indication for augmenting the bladder ${ }^{(\mathbf{1})}$.

Incontinence and urinary tract infections (UTIs), with or without vesicoureteral reflux, are associated symptoms that may benefit from augmentation cystoplasty. Although we prefer ileum in most cases, many different bowel segments have been used, each with its own specific advantages and disadvantages; however, no bowel segment is clearly superior in all circumstances. The most important factor is detubularization of the bowel to reduce intravesical pressure from peristalsis or mass contractions ${ }^{(\mathbf{1})}$.

However the use of gastrointestinal tissue for augmentation cystoplasty is associated with numerous complications like increased mucus production, infection, stone formation, perforation, metabolic disturbances and rarely even malignant changes. So the ideal substitute for bladder augmentation remains the bladder tissue itself which unfortunately is unavailable in cases of small capacity urinary bladder ${ }^{(2)}$.

Patient selection remains an important issue before augmentation cystoplasty.
Chronic renal failure (as documented by creatinine clearance) is a relative contraindication to bowel augmentation because both the small and large bowel resorb many urinary solutes that may cause deterioration of the metabolic status of the patient ${ }^{(1)}$.

Alternatives to conventional enterocystoplasty have been developed in order to avoid the most common complications derived from contact of the urine with intestinal mucosa ${ }^{(3)}$.

Recognizing the frequency of cases, especially in PUV and neuropathic bladders, in which the small capacity-high pressure bladder is associated with a large-urothelium lined megaureter, we conclude that ureterocystoplasty can be useful in selected cases when a large dilated ureter is available. Seromuscular colocystoplasty lined with urothelium (SCLU) has been urodynamically effective in several series when the outlet resistance is high and no additional intravesical procedures are necessary. Sero-muscular gastrocystoplasty lined with urothelium seems to offer no distinct advantages and involves a much more involved operation. The use of seromuscular segments with-out urothelial preservation, with or without the use of an intravesical balloon has been reported as successful in two centers but strict urodynamic evidence of its effectiveness is lacking. The published evidence argues strongly against the use of detrusorectomy or detrusorotomy alone because of the lack of significant urodynamic benefits. Two recent reports discourage the use of small intestinal submucosa patches because of a high failure rate. Finally, research into the development of a bioengineered bladder constructed with cell harvested from the same patient continues but is fraught with technical and conceptual problems. In conclusion of the methods reviewed, only ureterocystoplasty and SCLU have been proven urodynamically effective and reproducible ${ }^{(3)}$. 
Although the original reports regarding ureterocystoplasty were extremely favorable, we became concerned with the results of this procedure as our experience with this operation increased. We were frequently finding ourselves faced with the need to perform re-augmentation after ureterocystoplasty. Attempts to assess the efficacy of and/or identify which patients would be best suited for this procedure by reviewing the published literature were fraught with problems. Publications regarding this operation frequently made No mention if preoperative urodynamic evaluations were performed in the presence or absence of a refluxing megaureter. To assess if the operation was successful was difficult to interpret because of a failure to standardize preoperative evaluations and urodynamic end points among the various publications ${ }^{(\mathbf{4})}$.

\section{AIM OF THE STUDY:}

To compare the outcomes of augmentation ureterocystoplasty in patients with dilated ureters to conventional augmentation iliocystoplasty

\section{PATIENTS AND METHODS:}

\section{Study Design:}

This is a prospective study which will include 20 patients divided into 2 groups

Group 1 undergoing ureterocystoplasty

Group 2 undergoing iliocystoplasty

Done in Ain Shams University Hospital, Urology Department.

Inclusion Criteria are Low bladder capacity and/or compliance, failure of conservative measures, unilateral or Bilateral dilated ureters.

Exclusion Criteria are normal bladder capacity and compliance, patientswith non ablated PUV, renal failureorimpairment, insufficiently dilated ureters.

\section{Methods:}

Preoperative work up includes history asserting on voiding troubles and continence issues, comprehensive physical examination, blood chemistry including S.creatinine and BUN, pelviabdominal ultrasound, pressure flow cystometry, ascending andmicturating urethrocystogram, intravenous pyelography in patients with no reflux, and radioisotope scan in obstructed ureters

An informed consent wassigned and all patients underwentuni or bilateral ureterocystoplasty.

Some associated procedures were performed; Patients with dilated ureter of a non-functioning kidney underwent simaltaneous nephrectomy and the use of the entire ureter for ureterocystoplasty or as needed to provide a high capacity low pressure reservoir, the other ureter may be reimplanted in case of high grade reflux or obstruction, patients with bilaterally dilated ureters underwent distal ureteric ureterocystoplasty and the proximal ureters were reimplanted in the augmented bladder, continent cutaneous diversion was performed in children or as needed

\section{Follow up:}

At 6 months postoperative all patients underwent blood chemistry, urodynamic evaluation, ascending cystourethrogram and ultrasound to assess the resolution of the degree of hydronephrosis.

\section{Analysis of data:}

Results were recorded and the Patients were compared with their preoperative data to assess the degree of improvement in compliance and maximum cystometric capacity then the 2 groups were compared according to degree of improvement in each of them.

\section{Ethical Considerations:}

The study was presented for approval from the ethical committee of the Faculty of medicine, Ain shams university. 
- Informed written consent was taken before recruitment in the study after explaining the purpose and procedures of the study.

- The privacy of participants and confidentiality of data were guaranteed during the various phases of the study.

- Any participant does not have to take part in this research if he or she wanted, they may stop participating at any time.

- The study was approved by the Ethics Board of Ain Shams University.

\section{Statistical Analysis Method:}

Recorded data were analyzed using the statistical package for social sciences, version 20.0 (SPSS Inc., Chicago, Illinois, USA). Quantitative data were expressed as mean \pm standard deviation (SD). Qualitative data were expressed as frequency and percentage.

The study was performed on 20 patients presenting to urology clinic in Ain Shams University Demerdash Hostpital

The patients were initially divided into 2 groups, the first group underwent ureterocystoplasty and the second group underwent iliocystoplasty, the first group (ureterocystoplasty) were further subdivided according to the method of ureterocystoplasty used, group Ia had ureterocysoplasty with the use of the dilated distal 5-8 cm of both ureters while group IIa underwent ureterocystoplasty with the entire ureter of a non-functioning kidney with simultaneous nephrectomy.

The mean follow up period was 20 months (range 12-26 months), there was no operative mortality, as regards the postoperative complications, 1 patient in group 1 and 1 patient in group 2 had wound infection that were managed conservatively, symptomatic UTI were encountered in 6 patients (2 in group 1 and 4 in group 2) in the first 12 months and were managed successfully with antibiotics guided by urine culture and sensitivity, during the early postoperative period, all patients of group 2 had excessive mucus production with frequent blockage of the urethral catheter, no patients required reaugmentation to date.

Preoperatively, 14 out of the 20 patients of the study were incontinent (7 of group 1 and 7 of group 2), postoperatively the continence improved in all patients of both groups despite the requirement of CIC in 5 patients in group 2 and 4 patients in group 1, this difference is however statistically insignificant with a $\mathrm{P}$ value $>0.05$, at the end of the follow up period, hydronephrosis was decreased or resolved in all patients

\section{RESULTS:}

The results of the present study are demonstrated in the following tables and figures.

Table (1):Comparison between three groups according to demographic data.

\begin{tabular}{|c|c|c|c|c|c|}
\hline $\begin{array}{c}\text { Demographic } \\
\text { data }\end{array}$ & $\begin{array}{c}\text { Group Ia: } \\
\text { Ureterocystoplasty }\end{array}$ & $\begin{array}{c}\text { Group Ib: } \\
\text { Ureterocystoplasty } \\
\text { with complete ureter of } \\
\text { non functioning kidney }\end{array}$ & $\begin{array}{l}\text { Group II: } \\
\text { Iliocystoplasty }\end{array}$ & $\mathrm{F} / \mathrm{x} 2 \#$ & p-value \\
\hline \multicolumn{6}{|l|}{ Age (years) } \\
\hline Mean \pm SD & $9.50 \pm 4.32$ & $9.00 \pm 4.08$ & $9.10 \pm 3.57$ & \multirow[t]{2}{*}{0.026} & \multirow[t]{2}{*}{0.974} \\
\hline Range & $4-15$ & $4-14$ & $3-15$ & & \\
\hline \multicolumn{6}{|l|}{ Sex } \\
\hline Female & $2(33.3 \%)$ & $1(25.0 \%)$ & $4(40.0 \%)$ & \multirow[t]{2}{*}{$0.293 \#$} & \multirow[t]{2}{*}{0.864} \\
\hline Male & $4(66.7 \%)$ & $3(75.0 \%)$ & $6(60.0 \%)$ & & \\
\hline
\end{tabular}


This table shows no statistically according to demographic data. significant difference between groups

Table (2): Comparison between three groups according to compliance ( $\mathrm{ml} / \mathrm{cm} \mathrm{h2o).}$

\begin{tabular}{|c|c|c|c|c|c|}
\hline $\begin{array}{l}\text { Compliance (ml/cm } \\
\text { h2o) }\end{array}$ & $\begin{array}{l}\text { Group Ia: Uretero- } \\
\text { cystoplasty }\end{array}$ & $\begin{array}{l}\text { Group Ib: Uretero- } \\
\text { cystoplasty with } \\
\text { complete ureter of } \\
\text { non functioning } \\
\text { kidney }\end{array}$ & $\begin{array}{l}\text { Group II: Ilio- } \\
\text { cystoplasty }\end{array}$ & ANOVA & p-value \\
\hline \multicolumn{6}{|c|}{ 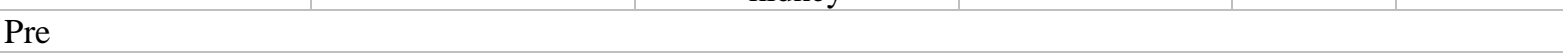 } \\
\hline Mean \pm SD & $16.00 \pm 5.37$ & $14.25 \pm 3.30$ & $15.10 \pm 3.60$ & \multirow{2}{*}{0.219} & \multirow[t]{2}{*}{0.806} \\
\hline Range & $10-25$ & $10-18$ & $10-20$ & & \\
\hline \multicolumn{6}{|l|}{ Post } \\
\hline Mean \pm SD & $26.67 \pm 5.50$ & $37.50 \pm 6.45^{\dagger}$ & $40.80 \pm 4.02^{\dagger}$ & \multirow[t]{2}{*}{15.348} & \multirow[t]{2}{*}{$<0.001^{* *}$} \\
\hline Range & $20-35$ & $30-45$ & $35-45$ & & \\
\hline \multicolumn{6}{|l|}{ Mean Difference } \\
\hline Mean \pm SD & $10.67 \pm 1.21$ & $23.25 \pm 6.40^{\dagger}$ & $25.70 \pm 5.29^{\dagger}$ & 19.572 & $<0.001^{* *}$ \\
\hline \multicolumn{6}{|l|}{$\%$ of improvement } \\
\hline Mean \pm SD & $72.43 \% \pm 21.81$ & $174.40 \% \pm 84.99^{\dagger}$ & $186.00 \% \pm 84.53^{\dagger}$ & \multirow[t]{2}{*}{4.948} & \multirow[t]{2}{*}{$0.020 *$} \\
\hline Range & $40-100$ & $114.3-300$ & $122.2-350$ & & \\
\hline Paired sample t-test & 21.574 & 7.269 & 15.356 & & \\
\hline p-value & $<0.001^{* *}$ & $0.005^{*}$ & $<0.001^{* *}$ & & \\
\hline
\end{tabular}

F-One Way Analysis of Variance; p-value $>0.05 \mathrm{NS}$; ${ }^{*}$-value $<0.05 \mathrm{~S}$; **p-value $<0.001 \mathrm{HS}$

Post HOC: $\uparrow$ significant with group Ia, $\neq$ significant difference with group Ib

This table demonstrates that there was a statistically significant improvement in compliance in all groups postoperative.

By comparing the mean increase in compliance in the three groups
There was statistically significant difference in the degree of improvement between group Ia (72\%) and the other 2 groups (group Ib was $174 \%$ and group II was $186 \%)$

Table (3): Comparison between three groups according to cystometric capacity.

\begin{tabular}{|c|c|c|c|c|c|}
\hline Cystometric capacity & $\begin{array}{c}\text { Group Ia: } \\
\text { Ureterocystoplasty }\end{array}$ & $\begin{array}{c}\text { Group Ib: } \\
\text { Ureterocystoplasty } \\
\text { with complete ureter } \\
\text { of non functioning } \\
\text { kidney } \\
\end{array}$ & $\begin{array}{l}\text { Group II: } \\
\text { Iliocystoplasty }\end{array}$ & ANOVA & p-value \\
\hline \multicolumn{6}{|c|}{ (r) } \\
\hline Mean \pm SD & $250.00 \pm 41.95$ & $215.00 \pm 65.57$ & $262.00 \pm 95.20^{\dagger}$ & \multirow[t]{2}{*}{3.879} & \multirow[t]{2}{*}{$0.041^{*}$} \\
\hline Range & $100-200$ & $150-300$ & $150-400$ & & \\
\hline \multicolumn{6}{|l|}{ Post } \\
\hline Mean \pm SD & $391.67 \pm 37.64$ & $507.50 \pm 53.77^{\dagger}$ & $661.00 \pm 116.38^{\dagger \neq}$ & \multirow[t]{2}{*}{31.632} & \multirow{2}{*}{$<0.001^{* *}$} \\
\hline Range & $250-350$ & $450-580$ & $500-900$ & & \\
\hline \multicolumn{6}{|l|}{ Mean Difference } \\
\hline Mean \pm SD & $141.67 \pm 39.71$ & $292.50 \pm 97.43^{\dagger}$ & $399.00 \pm 146.25^{\dagger \neq}$ & 9.235 & $<0.001 * *$ \\
\hline \multicolumn{6}{|l|}{ \% of improvement } \\
\hline Mean \pm SD & $105.13 \% \pm 54.94$ & $155.20 \% \pm 94.13^{\dagger}$ & $183.69 \% \pm 111.00^{\dagger}$ & \multirow[t]{2}{*}{3.290} & \multirow[t]{2}{*}{$0.029 *$} \\
\hline Range & $50-200$ & $66.7-286.7$ & 47.4-366.7 & & \\
\hline Paired sample t-test & 8.739 & 6.005 & 8.628 & & \\
\hline$p$-value & $<0.001 * *$ & 0.009* & $<0.001 * *$ & & \\
\hline
\end{tabular}

F-One Way Analysis of Variance; $p$-value $>0.05 \mathrm{NS} ;{ }^{*} p$-value $<0.05 \mathrm{~S} ;{ }^{* *}$-value $<0.001 \mathrm{HS}$

Post HOC: $†$ significant with group Ia, $\neq$ significant difference with group Ib

This table demonstrates that there was a statistically significant improvement in cystometric capacity at less than $30 \mathrm{~cm} \mathrm{H2O}$ intravesical pressure in all groups postoperative. 
By comparing the mean increase in capacity in the three groups

There was statistically significant difference in the degree of improvement between group Ia (105\%) and the other 2 groups (group Ib was $155 \%$ and group II was $183 \%)$.

Table (4): Comparison between the two ureterocystoplasty groups according to mean ureteric diameter.

\begin{tabular}{|l|l|l|l|l|}
\hline \multicolumn{1}{|c|}{ Mean ureteric diameter } & \multicolumn{1}{|c|}{$\begin{array}{c}\text { Group Ia: } \\
\text { Ureterocystoplasty }\end{array}$} & $\begin{array}{c}\text { Group Ib: } \\
\text { Ureterocystoplasty } \\
\text { with complete ureter of } \\
\text { non functioning kidney }\end{array}$ & t-test & p-value \\
\hline Mean \pm SD & $2.33 \pm 0.41$ & $1.83 \pm 0.24$ & 4.957 & 0.057 \\
\hline Range & $2-3$ & $1.5-2$ & \\
\hline t-Independent Sample t-test $; \quad p$-value $>0.05 N S$ &
\end{tabular}

t-Independent Sample t-test; $\quad$-value $>0.05 \mathrm{NS}$.

This table shows no statistically significant difference between groups according to mean ureteric diameter.

\section{DISCUSSION:}

Largely because of the complications of entero-cystoplasty, alternative methods that can achieve a large-capacity, compliant reservoir remain attractive. Efforts have covered the spectrum from synthetic materials and autologous grafts through creation of a bladder diverticulum (autoaugmentation) to various forms of neural stimulation. Some of these alternatives appear to hold promise, but none have stood the test of time in comparison to intestinal cystoplasty.

An ideal tissue for increasing capacity and improving compliance would have transitional epithelium so as to be relatively impermeable and avoid metabolic changes. The lining would also not produce mucus and would carry no increased potential for tumor development. Two such alternative procedures are ureterocystoplasty and autoaugmentation. The natural characteristics of the ureter, namely its elasticity, a wall of smooth muscle and a urothelial lining made it a very attractive augmentation material. The first clinical report of ureterocystoplasty was published in 1973 by Eckstein and Martin who described the use of a longitudinally incised ureter to augment the bladder of a 7-month-old infant. The technique was revived enthusiastically in the early 1990s by four independent groups and was attractive on several levels. Since the urothelium was pre-served, acid-base disturbances and mucus production were not a problem. Further-more, the procedure could be per-formed using an exclusively extraperitoneal approach. The inherent drawback however was the limitation in its applicability.

As regard the demographic data the mean patient age in our study was 9 with a range of 4-15 years old, the study included 13 males and 7 females (65\% males and $35 \%$ females)

Zubieta et al. ${ }^{(5)}$ reported mean patient age in their study of 9 years with range of 4 months to 20 years, other authors also reported similar age groups like Pascual et al. ${ }^{(6)}$ who reported mean age of 7.2 years with a range of 1.5-15.7 years and Kajbafzadeh et al. ${ }^{(7)}$ who had mean age of 7.3 years with a range of 4-9 years, the higher frequency of cases with megaureter in early childhood probably explains the age group that is demonstrated in most studies, the higher male to female ratio was also demonstrated in most similar studies, such as Hitchcock et al. ${ }^{(8)}$ who reported male to female ratio of 5:3 and Tekgul et al. ${ }^{(9)}$ who had a male to female ratio of $4: 2$, the male predominance in most studies may be due to 
cases of PUV which frequently require augmentation.

As regards the urodynamic outcome in the present study we found that the improvement in capacity and compliance was significant with either ureterocystoplasty or iliocystoplasty, however there was significant discrepancy according to the amount of ureteric tissue available for augmentation.

When 1 entire ureter was used the mean improvement in compliance $(+174 \%)$ was comparable to the improvement with iliocystoplasty $(+186 \%)$

When we used only the distal 5-8 $\mathrm{cm}$ of both ureters there was still significant improvement $(+72 \%)$ however the result is significantly lower than the use of an entire ureter or ileum for augmentation.

As regards the cystometric capacity at less than $30 \mathrm{~cm} \mathrm{H}_{2} \mathrm{O}$ the discrepancy in improvement was less remarkable between the use of an entire ureter for ureterocystoplasty $(+155 \%)$ versus the use of the distal part of 2 ureters $(+105 \%)$, however both were lower than the degree of improvement with iliocystoplasty $(+183 \%)$

Similar results were found with several authors such as Landau and colleagues ${ }^{(10)}$ who showed urodynamic outcomes to be comparable to those of ileocystoplasty in an age-matched control group. Specifically, the mean pressure specific volume at $30 \mathrm{~cm}$ $\mathrm{H}_{2} \mathrm{O}$ was found to be $413 \mathrm{ml}$ for the ileocystoplasty and $380 \mathrm{ml}$ for the ureterocystoplastygroups respectively.

Bladder compliance was found to be normal in $87.5 \%$ of patients following ureterocystoplasty. In a study by Johal et al. ${ }^{(11)}$. Urodynamic evaluation showed an improvement in mean bladder capacity after ureterocystoplasty from 125 to $292 \mathrm{ml}$ and in mean compliance from 2.1 to $16.2 \mathrm{ml} / \mathrm{cm}$ $\mathrm{H}_{2} \mathrm{O}$.
In another study by Youssif et al. ${ }^{(12)}$ which included 8 boys who underwent ureterocystoplasty it was reported that all patients had significant improvement in capacity and compliance postoperative, Bladder capacity (as measured during cystometry less than $30 \mathrm{~cm} \mathrm{H}_{2} \mathrm{O}$ ) was increased from a mean of 107 CC preoperatively to 288 cc postoperatively. This increase was significant with a P-value of 0.001. Also, compliance was significantly improved in all patients postoperatively $(\mathrm{P}=$ 0.001)The author did not find any significant difference when the whole ureter of a nonfunctioning kidney is used or only the dilated parts of 1 or 2 ureters were used, the author mentioned that the diameter of the ureters used for augmentation were always more than $1 \mathrm{~cm}$, he did not mention however their exact diameter or their length, which could potentially explain that the author achieved good results with even a part of 1 dilated ureter.

Many other studies also presented favorable outcomes with ureterocystoplasty including the study by Kajbafzadeh et al. ${ }^{(7)}$ that included 13 patients who underwent "teapot" ureterocystoplasty and ureteral Mitrofanoff channel, they reported that mean bladder capacity at pressure less than $30 \mathrm{~cm}$ $\mathrm{H} 2 \mathrm{O}$ showed a significant postoperative increase from $128 \mathrm{ml}$ to $335 \mathrm{ml}$. Compliance also increased from $8 \mathrm{ml} / \mathrm{cm} \mathrm{H} 2 \mathrm{O}$ to 25 $\mathrm{ml} / \mathrm{cm} \mathrm{H} 2 \mathrm{O}$. However, the authors reported the use of markedly dilated ureter (mean of $5.5 \mathrm{~cm}$ with a range of 3.6 to $7.7 \mathrm{~cm}$ ) and they concluded that the method is suitable only when the ureters are dilated more than $3 \mathrm{~cm}$ to avoid shortage of ureteric tissue for augmentation and Mitrofanoff creation.

A South American study by Pascual et al. ${ }^{(6)}$ specifically reported the results of using a single dilated distal ureter for augmentation ureterocystoplasty (and transuretero-ureterostomy) in 22 pediatric patients with variable diagnoses, they reported average increase in bladder 
capacity at less than $30 \mathrm{~cm}$. pressure of $177 \%$ (range $11 \%$ to $560 \%$ ). The authors did not however mention any comparison of mean compliance before and after the surgery, in contrast to our study, this study showed good results after augmentation with a segment of 1 ureter, but in this study the authors had to use relatively longer segments (mean of $11 \mathrm{~cm}$ with a range of 9-14 cm) to compensate for the use of a single ureter which was not very markedly dilated (mean of $1.3 \mathrm{~cm}$ in diameter with a range of $0.8-2.5$ $\mathrm{cm})$

Another South American study that was conducted in 2 centers in Chile and Argentina by Zubieta et al.(5) included 32 patients, the author of this study reported no significant variation in the outcome whether 1 or 2 ureters were used for augmentation, they reported that the improvement in capacity was significantly higher if 1 or 2 whole ureters were used versus the improvement if only a segment of a distal ureter is used but they concluded that although the increase in bladder capacity (mean of $230 \%$ in this series) is not always optimal with the use of a distal dilated ureter, it is good enough to ensure a good clinical outcome. The drawbacks of this study was that it made no mention of the size or diameter of the ureters used for augmentation and did not compare the mean compliance between the 3 groups, this study shared some authors with the aforementioned study by Pascual et al. ${ }^{(6)}$

Husmannet al. ${ }^{(4)}$ conducted a retrospecttive multicenter study including 64 patients operated with various techniques. They concluded that in patients with non-refluxing megaureters with an ultrasonographic diameter greater than $1.5 \mathrm{~cm}$ had universal success when the entire ureter was used for the augmentation. In this series, the group of patients in whom a dilated distal ureter was used resulted in poor augmentation and the need to re-augment the bladder was $92 \%$.
We noticed in our study that the urodynamic outcome of augmentation is directly related to the amount of ureteral tissue used for augmentation, this observation is consistent with the results reported by Husmann et al. ${ }^{(4)}$ but is not consistent with findings by the aforementioned study by Zubieta et al. ${ }^{(5)}$, probably due to differences in ureteral diameter and length used for augmentation which were not mentioned in the study.

As regard the ureteral diameter the mean ureteral diameter in our study was 2.1 $\mathrm{cm}$ with a range of $1.5-3 \mathrm{~cm}$, Husmann et al. ${ }^{(4)}$ reported poor results of ureterocystoplasty if ureteral diameter was less than 1.5 $\mathrm{cm}$, whether 1 or 2 ureters were used for augmentation and reported that all patients who underwent ureterocystoplasty with ureters of diameters less than $1.5 \mathrm{~cm}$ will require reaugmentation, they reported good success rate when the ureteric diameter was $1.5 \mathrm{~cm}$, in another study by Kajbafzadeh et al. ${ }^{(7)}$ they reported good results with ureteral diameters of more than $3 \mathrm{~cm}$, the mean ureteral diameter in the study was $5.5 \mathrm{~cm}$ with a range 3.6-7.1, most studies report that adequate augmentation is directly proportional to the preoperative ureteral diameter.

As regards the postoperative complications in our study the most frequent short term complication in patients who underwent iliocystoplasty was frequent blockage of the catheter in nearly all patients, other short term complications included wound infection in 2 patients with similar rate in both iliocystoplasty and ureterocystoplasty, and symptomatic urinary tract infection in 2 patients who underwent ureterocystoplasty and 4 patients who underwent iliocystoplasty.

Kajbafzadeh et al. ${ }^{(7)}$ reported urine leakage from the Mitrofanoff stoma, which was treated with a bioceramic paste injected into the submucosa via the Mitrofanoff channel as the only surgical complication, Hitchcock et al. ${ }^{(8)}$ reported renal fossa 
haematoma which needed surgical drainage but subsequently made an uneventful recovery. In the same series patient with high output renal failure prolapsed the Mitrofanoff stoma which became incontinent and required revision which was successful with a follow-up of 8 months. 3 out of 8 patients patients suffered from recurrent UTI. In other series of 8 patients undergoing ureterocysoplasty, Youssif et al. ${ }^{(12)}$ reported symptomatic UTI requiring hospital admission as the only postoperative complication. Out of 22 patients in the study by Pascual et al. ${ }^{(6)} 6$ patients had symptomatic UTI postoperatively, other surgical complications in this study included spontaneous perforation of the ureteral patch in 1 patient requiring colocystoplasty, Tegkul et $\mathrm{al}^{(9)}$ reported no complications in a series of 6 children who underwent ureterocystoplasty. Zubietaet al. $^{(5)}$ reported that the most common postoperative complication was symptomatic urinary infection after catheter removal in 12 out of 32 patients who underwent ureterocystoplasty. In a patient on hemodialysis acute bleeding developed after cystostomy catheter removal, requiring an endoscopic procedure for evacuating the clots to control bleeding as well as a blood transfusion, also 1 patient underwent reoperation after augmentation due to stenosis of the transureteroureterostomy anastomosis. Differences in sample size, careful surgical techniques and proper antiseptic precautions with various surgeons in different centers probably explain the variable complication rate between different studies including our study.

As regards continence and CIC requirement in our study there was significant improvement in postoperative continence in both groups, and there was no significant difference in the requirement for CIC in both groups, with 9 patients out of 20 patients in both groups requiring regular postoperative CIC.
Similar results were reported in various studies, Youssif et al. ${ }^{(12)}$ reported good continence in all of 8 patients who underwent ureterocystoplasty, however 4 of them required regular CIC for adequate bladder emptying, Pascual et al. ${ }^{(6)}$ documented adequate continence in 19 of 22 patients who underwent ureterocystoplasty, all of them are maintained on CIC, in their study of 13 patients who underwent teapot ureterocystoplasty Kajbafzadeh et al. ${ }^{(7)}$ reported good continence in all 13 patients, 12 of them required CIC while the remaining 1 patient was voiding spontaneously. Of the 6 patients in the study by Tegkul et al. ${ }^{(9)} 4$ patients voided spontaneously as they were neurologically normal, the remaining 2 patients required CIC for continence, most studies correlate the CIC requirement to the presence of neurological impairment, however, despite the requirement for CIC most studies agree with our result that achieving good continence after ureterocystoplasty is feasible in most cases.

As regards resolution of hydronephrosis in our study there was an improvement in all patients in the degree of hydronephrosis, patients with milder degrees of hydronephrosis showed resolution of hydronephrosis in follow up, comparable results have been reported by Pascual et al. ${ }^{(6)}$ who reported improvement in the degree of hydronephrosis in 20 out of 22 patients, and also by Zubieta et al. ${ }^{(5)}$ who reported improvement in hydronephrosis in all patients who received a complete ureter, in patients who received distal segment of 1 ureter they reported 92\% improvement, similar favorable outcome was reported by Kajbafzadeh et al. ${ }^{(7)}$ who reported adequate improvement in the degree of reflux after ureterocystoplasty in 13 patients, in general there is a favorable outcome on the upper tracts when adequate ureterocystoplasty was performed. 


\section{Conclusion:}

When considering a patient for bladder augmentation, proper selection of patients for either iliocystoplasty or ureterocystoplasty remains highly important, when an entire megaureter of a non-functioning kidney is used for bladder augmentation the results are comparable to iliocystoplasty and a good clinical outcome is guaranteed for most patients, when such a scenario is not found and bladder augmentation is performed with segments of 1 or 2 ureters, the results are variable among the different studies and no conclusion can be made regarding the cutoff of safe diameter or length to achieve sufficient bladder augmentation, this subject remains a matter of debate and further studies are needed in this category of patients to document the safest cutoff value of ureteral dilatation to be used for ureterocystoplasty.

\section{REFERENCES:}

1. Graham SD, Keane TE, Glenn JF. Glenn's Urologic Surgery, Augmentation Cystoplasty in Children, Hans GP (ed.). $6^{\text {th }}$ edition, ch 111, Lippincott Williams \& Wilkins, 2004, p. 857.

2. Singh $V$, Sinha RJ and Sankhwar SN. Ureterocystoplasty: a novel approach to augment small capacity urinary bladder in adults. Indian J Surg 2009; 71:151-153.

3. Gonzalez $R$ and Ludwikowski BM. Alternatives to conventional enterocystoplasty in children: a critical review of urodynamic outcomes. Frontiers in Pediatrics 2013; 1(25): 1-9.

4. Husmann DA, Snodgrass WT, Koyle MA, Furness PD, Kropp BP, Cheng EY, et al. Ureterocystoplasty: indications for a successful augmentation. The Journal of Urology 2004; 171(1): 376-380.
5. Zubieta R, De Badiola F, Escala JM, Castellan M, Puigdevall JC, Ramírez K, et al. Clinical and urodynamic evaluation after ureterocystoplasty with different amounts of tissue. The Journal of Urology 1999; 162(3 Part 2): 1129-1132.

6. Pascual LA, Sentagne LM, VegaPerugorría JM, de Badiola FI, Puigdevall $J C$, Ruiz E. Single distal ureter for ureterocystoplasty: a safe first choice tissue for bladder augmentation. The Journal of Urology 2001; 165(6 Part 2): 2256-2258.

7. Kajbafzadeh AM, Farrokhi-Khajeh-Pasha $Y$, Ostovaneh MR, Nezami BG, Hojjat A. Teapot ureterocystoplasty and ureteral Mitrofanoff channel for bilateral megaureters: technical points and surgical results of neurogenic bladder. The Journal of Urology 2010; 183(3): 1168-1176.

8. Hitchcock RJI, Duffy PG, Malone PS. Ureterocystoplasty: the 'bladder' augmentation of choice. British Journal of Urology 1994; 73(5): 575-579.

9. Tekgül S, Öge Ö, Bal K, Bakkaloğlu M. Ureterocystoplasty: an alternative reconstructive procedure to enterocystoplasty in suitable cases. Journal of Pediatric Surgery 2000; 35(4): 577-579.

10. Landau EH, Churchill BM, Jayanthi VR, et al. The sensitivity of pressure specific bladder volume versus total bladder capacity as a measure of bladder storage dysfunction. J Urol 1994; 152:1578-81.

11. Johal NS, Hamid R, Aslam $Z$ et al. Ureterocystoplasty: long-term functional results. J Urol 2008; 179: 2373.

12. Youssif M, Badawy H, Saad A, Hanno A, Mokhless I. Augmentation ureterocystoplasty in boys with valve bladder syndrome. Journal of Pediatric Urology 2007; 3(6), 433-437. 
تقييم تكبير المثانة باستخدام جزء من الحالب المتسع كبديل لتكبير المثانة باستخدام جزء من الاقاق

محمد شريف مراد، يوسف محمود قطب، احمد حفناوي محمد

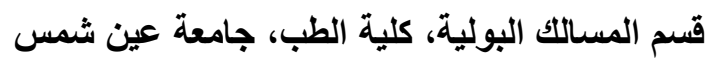

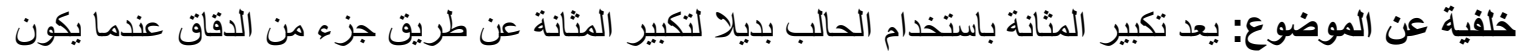

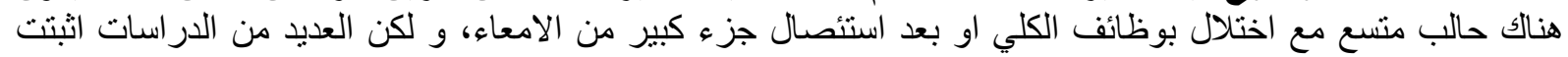
نتائج متفاوتة بعد تكبير المثانة باستخدام جزء بؤ من الحالب.

الهذف من العمل: هو مقارنة نتائج تكبير المثانة باستخدام من الحالب مع الطريقة التقليدية و هي تكبير المثانة

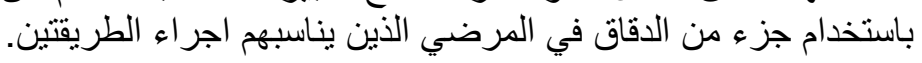

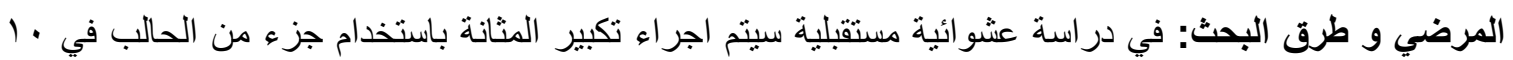

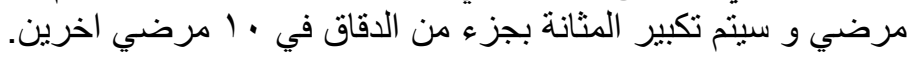



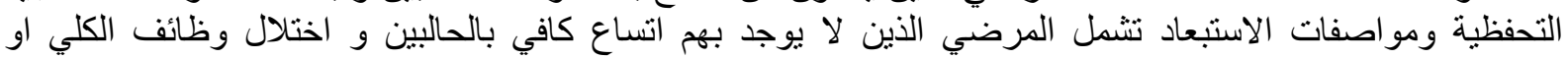
استئصال جزء كبير من الدقاق.

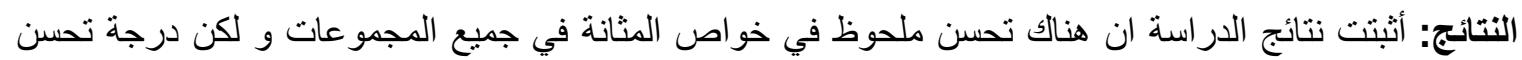

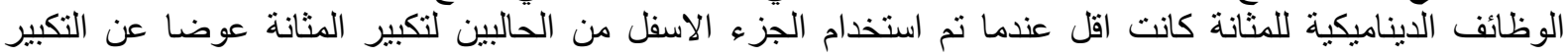

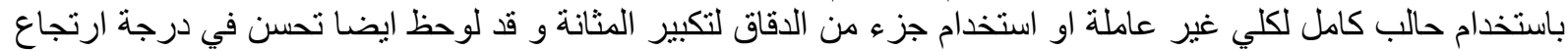

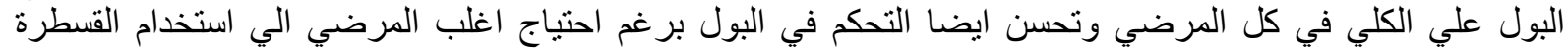
بشكل نظيف و متقطع، ولوحظ ان الحتمالية الالتهابات البولية كانت منساوية في الحالتين.

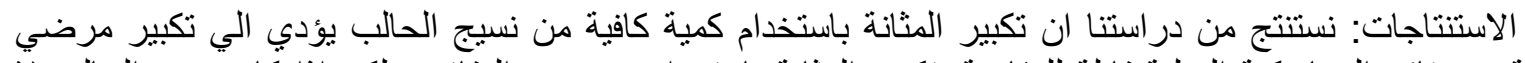

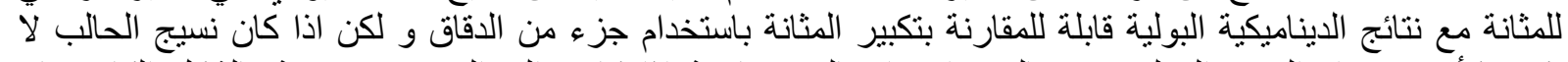

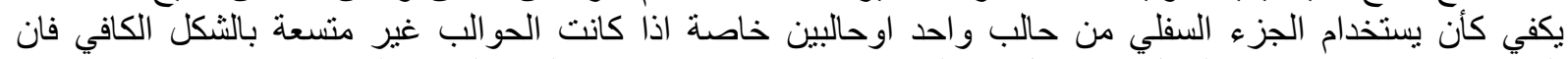
التحسن في نتائج ديناميكية التبول يكون اقل من التحسن عند استخدام جزء من الدقاق التهان التكبير المثانة. 